\title{
Consumption of dairy products and cardiovascular disease risk: results from the French prospective cohort NutriNet- Santé
}

Article

Accepted Version

Sellem, L., Srour, B., Jackson, K. G. ORCID:

https://orcid.org/0000-0002-0070-3203, Hercberg, S., Galan, P., Kesse-Guyot, E., Julia, C., Fezeu, L., Deschasaux-Tanguy, M., Lovegrove, J. and Touvier, M. (2021) Consumption of dairy products and cardiovascular disease risk: results from the French prospective cohort NutriNet-Santé. British Journal of Nutrition. ISSN 0007-1145 doi:

https://doi.org/10.1017/S0007114521001422 Available at https://centaur.reading.ac.uk/99737/

It is advisable to refer to the publisher's version if you intend to cite from the work. See Guidance on citing.

To link to this article DOI: http://dx.doi.org/10.1017/S0007114521001422

Publisher: Cambridge University Press

All outputs in CentAUR are protected by Intellectual Property Rights law, including copyright law. Copyright and IPR is retained by the creators or other copyright holders. Terms and conditions for use of this material are defined in 
the End User Agreement.

www.reading.ac.uk/centaur

\section{CentAUR}

Central Archive at the University of Reading

Reading's research outputs online 


\title{
Consumption of dairy products and cardiovascular disease risk: results from the French prospective cohort NutriNet-Santé
}

Laury Sellem ${ }^{1}$ (https://orcid.org/0000-0002-2697-997X), Bernard Srour ${ }^{2}$, Kim G. Jackson ${ }^{1}$, Serge Hercberg ${ }^{2,3}$, Pilar Galan², Emmanuelle Kesse-Guyot' ${ }^{2}$, Chantal Julia ${ }^{2,3}$, Léopold K. Fezeu², Mélanie Deschasaux $^{2}$, Julie Lovegrove ${ }^{1^{*}}(0000-0001-7633-9455)$, Mathilde Touvier ${ }^{2^{*}}$

\footnotetext{
1 Hugh Sinclair Unit of Human Nutrition, Department of Food and Nutritional Science, University of Reading, Whiteknights, Pepper Lane, Harry Nursten Building, Reading, RG6 6DZ

2 Sorbonne Paris Nord University, Inserm, INRAE, Cnam, Nutritional Epidemiology Research Team (EREN), Epidemiology and Statistics Research Center - University of Paris (CRESS), 93017 Bobigny, France

${ }^{3}$ Public Health Department, Avicenne Hospital, AP-HP, Bobigny, France.

* These authors share equal senior authorship; they are co-last authors.
}

Corresponding author: Dr Bernard Srour b.srour@eren.smbh.univ-paris13.fr (ORCID: 0000-00021277-3380)

Short version of the title: dairy consumption and cardiovascular disease risk

Keywords: dairy, cardiovascular disease, fermented dairy, cerebrovascular disease, cheese, yogurt

\begin{abstract}
In France, dairy products contribute to dietary saturated fat intake, of which reduced consumption is often recommended for cardiovascular disease (CVD) prevention. Epidemiological evidence on the association between dairy consumption and CVD risk remains unclear, suggesting either null or inverse associations. This study aimed to investigate the associations between dairy consumption (overall and specific foods) and CVD risk in a large cohort of French adults. This prospective analysis included participants aged $\geq 18$ years from the NutriNet-Santé cohort (2009-2019). Daily dietary intakes were collected using $24 \mathrm{~h}$-dietary records. Total dairy, milk, cheese, yogurts, fermented and reduced-fat dairy intakes were investigated. CVD cases $(n=1,952)$ included cerebrovascular ( $n=878$ cases) and coronary heart diseases (CHD, $n=1,219$ cases). Multivariable Cox models were performed to investigate associations. This analysis included $n=104,805$ French adults (mean age at baseline 42.8 years (SD 14.6), mean follow-up 5.5 years (SD 3.0, i.e. 579,155 persons years). There were no significant associations between dairy intakes and total CVD or CHD risks. However, the consumption of at least $160 \mathrm{~g} / \mathrm{d}$ of fermented dairy (e.g. cheese and yogurts) was associated with a reduced risk of cerebrovascular diseases compared to intakes below $57 \mathrm{~g} / \mathrm{d}$ ( $\mathrm{HR}=0.81$ [0.66-0.98], $\mathrm{p}$-trend=0.01). Despite being a major dietary source of saturated fats, dairy consumption was not associated with CVD or CHD risks in this study. However, fermented dairy was associated with a lower cerebrovascular disease risk. Robust randomized controlled trials are needed to further assess the impact of consuming different dairy foods on CVD risk and potential underlying mechanisms.
\end{abstract}




\section{Introduction}

2 Cardiovascular diseases (CVD), including coronary heart diseases (CHD) and cerebrovascular diseases such as strokes are still a leading cause of mortality worldwide, causing 17.9 million deaths every year ${ }^{(1),(2)}$. In France, CVDs are the primary cause of death in women and the second most common cause in men ${ }^{(3)}$. Beside smoking, lifestyle factors such as nutritional status and dietary habits, have been identified as one of the main modifiable risk factors of CVD ${ }^{(4)}$. Thus, public health guidelines around the world target the consumption of specific nutrients and food groups as a strategy for reducing CVD risk at a population level. In particular, reducing the dietary consumption of saturated fat (SFA) is often recommended to help lower circulating levels of low-density lipoprotein cholesterol, a well-established risk factor for CVD ${ }^{(5),(6)}$. In France, public health guidelines suggest a consumption of SFA below $12 \%$ of dietary energy (without alcohol), with an emphasis on three fatty acids that should remain below $8 \%$ of dietary energy (lauric C12:0, myristic C14:0 and palmitic C16:0 acids) ${ }^{(7)}$. In parallel, the French National Health and Nutrition Programme (PNNS) focuses on recommendations related to food groups, and suggests a daily consumption of two servings of dairy products per day for adults, to be chosen among milk, cheese and yogurts, but not including butter, cream or dairy desserts (e.g. custard, ice cream and cheese cake) ${ }^{(8)}$.

Dairy products are nutrient-rich foods containing various minerals and vitamins, such as calcium, potassium, phosphorus, and vitamins $B, K$ and $D$ which are associated with health benefits. However, full-fat dairy foods can also be energy-dense and may contain high levels of sodium and SFA. In French adults, dairy contribute to $24 \%$ of total dietary SFA intake ${ }^{(9)}$. Despite this high contribution to dietary SFA, epidemiological evidence on the association between dairy product consumption and CVD risk remains unclear. Recent meta-analyses of prospective cohort studies suggest either null or slightly inverse associations between total dairy foods and incident CVDs ${ }^{(10)-(13)}$. Similar trends were also observed in more recent prospective cohort studies, such as the PURE study, which included data from 21 countries across five continents and observed a reduced risk of CVD associated with total dairy consumption ${ }^{(14)}$. In addition, epidemiological evidence on specific types of dairy remains inconsistent, although a recent meta-analysis of nine prospective cohort studies suggested a reduced CVD risk associated with the consumption of fermented dairy foods only, which included cheese, yogurt and fermented milk, as opposed to intakes of total dairy or non-fermented milks ${ }^{(11)}$. These results raise the question of the importance of dairy food types and potential fermentation in relation to cardiovascular health.

This study aimed to investigate the associations between the consumption of dairy foods (overall and specific types) and CVD risk in a large cohort of French adults.

\section{Material and Methods}

\section{The NutriNet-Santé cohort}

The NutriNet-Santé study is an ongoing French web-based cohort, launched in 2009 with the aim of investigating the associations between nutrition, dietary behaviours, determinants of nutrition status, and health. Detail of this study has been published previously ${ }^{(15)}$. Briefly, since May 2009 participants aged 18 years and over with access to the Internet have been continuously recruited 
among the French population using vast multimedia campaigns. All questionnaires are completed online using a dedicated website (www.etude-nutrinet-sante.fr).

\section{Ethical approval}

The NutriNet-Santé study is conducted according to the Declaration of Helsinki guidelines. It was approved by the Institutional Review Board of the French Institute for Health and Medical Research (IRB Inserm n ${ }^{\circ} 0000388$ FWA00005831) and the "Commission Nationale de I'Informatique et des Libertés" (CNIL n908450/n909216). Each participant provides their informed consent electronically. The study is registered at clinicaltrials.gov as NCT03335644.

\section{Data collection}

Upon inclusion, participants completed a set of five questionnaires related to socio-demographic and lifestyle characteristics, such as sex, occupation, educational level ( $<$ high school degree, $<2$ years after high school, $\geq 2$ years after high school), smoking status (never smoked, former smoker, current smoker), alcohol consumption (g/d), number of children ${ }^{(16)}$, anthropometrics ${ }^{(17),(18)}$ (e.g. height and weight, which were validated against a random sample of participants), dietary intakes ${ }^{(19)}$, physical activity levels (as low, moderate of high, from validated seven day International Physical Activity Questionnaire (IPAQ)) ${ }^{(20),(21)}$, and health status (e.g. personal and family history of diseases, prescribed medication).

Dietary data

Usual dietary intakes were assessed at inclusion and then every six months, using a series of three non-consecutive web-based $24 \mathrm{~h}$-dietary records, randomly assigned over a 2-week period (2 weekdays and 1 weekend day). The web-based questionnaires used in the study have been tested and validated against both in-person interviews by trained dietitians, and urinary and blood markers (17),(22). In this analysis, we calculated the usual baseline dietary intakes as the average of all $24 \mathrm{~h}$ dietary records completed during the first two years of each participant's follow-up, with a mandatory requirement of at least two $24 \mathrm{~h}$-dietary records during this period to be included in the analysis.

At all times throughout their assigned dietary record period, participants had access to a dedicated interface of the study website to declare all foods and beverages consumed during a $24 \mathrm{~h}$-period: three main meals (breakfast, lunch, dinner) and any other eating occasion. When participants could not provide weights for the food items consumed, they were invited to estimate portion sizes using validated photographs or usual containers ${ }^{(23)}$. A French food composition database ( $>3,500$ items) ${ }^{(24)}$ was used to estimate mean daily energy, alcohol, macro- and micro-nutrient intakes. These estimates included contributions from composite dishes using French recipes validated by food and nutrition professionals. Individual dietary data were not communicated to participants to avoid any changes in dietary behaviours. Finally, those that under-reported total energy intake were identified and excluded based on the method proposed by Black ${ }^{(25)}$, using the basal metabolic rate, Goldberg cut-off, and a physical activity level (PAL) cut-off of 1.55 which corresponds to the WHO value for "light" activity. For this calculation, intra-individual coefficients of variations for BMR and PAL were fixed using the values recommended by Black, i.e. $8.5 \%$ and $15 \%$, respectively. About $20.0 \%$ of 
participants of the cohort were considered as under-reporters of energy intake and were excluded from the analyses. There was no sign of over reporters as the highest energy intakes ranged within plausible values $\left(99^{\text {th }}\right.$ percentile $\left.=3,289 \mathrm{kcal} / \mathrm{d}\right)$.

\section{Dairy products classification}

Trained dietitians categorised all dairy foods of the NutriNet-Sante composition table into one of the five dairy groups defined in the PNNS: milk, cheese, yogurts, curd cheese and "petit-suisses". As per the PNNS guidelines, milk-based products containing more than $12 \%$ of sugars were classified in a separate "dairy desserts" category, while creams and butter which were considered as fat sources. Thus, these three food groups were not included in this analysis. We calculated a larger "yogurt-like dairy products" category which included the consumption of yogurt along with curd cheese and petit-suisses, as those were not consumed frequently enough to be analysed separately. Total dairy intakes were calculated by combining the consumption of each of the five dairy groups (milk, cheese, yogurt, curd cheese and "petit-suisses"). In addition, we defined fermented dairy foods as cheese, curd cheese, petit-suisses, yogurts and fermented milk, whereas non-fermented dairy included all milks (UHT, pasteurised, concentrated and flavoured) except fermented ones. Finally, reduced-fat dairy products included skimmed and semi-skimmed milk, low-fat yogurts, curd cheese, petit-suisses and cheese containing less than $20 \mathrm{~g}$ of fat per $100 \mathrm{~g}$ final product.

\section{Case ascertainment}

Participants were invited to declare any major health event on a dedicated interface on the study website, either through the yearly health status questionnaire, through a specific health check-up questionnaire sent out every three months, or spontaneously. We asked participants to send their medical records (e.g. complementary examinations for diagnosis, hospitalisations and electrocardiograms) to support any health event declaration. A physician expert committee validated every major health event after reviewing the participants' medical records and collecting additional information from the participants' treating physicians or medical practices. In the absence of any response to the study website for more than one year, the physician expert committee contacted the participants' family or physicians. In addition to this process, which constituted the main source of case ascertainment, cohort data from participants was linked to medicoadministrative databases from the National Health Insurance (SNIIRAM, authorisation by the Council of State No 2013-175). Finally, deaths and potentially missed CVD events in deceased participants were identified using data from the French national cause-specific mortality registry (CépiDC).

The International Classification of Diseases-Clinical Modification codes (ICD-CM, $10^{\text {th }}$ revision) was used to classify CVD cases. This study focused on first incident cases of myocardial infarction (121), angioplasty (Z95.8), acute coronary syndrome (I20.0 and I21.4), angina pectoris (I20.1, I20.8 and 120.9), stroke (164) and transient ischemic attack (TIA, G45.8 and G45.9) occurring between inclusion and January 2019. CHD included all cases of myocardial infarction, angioplasty, acute coronary syndrome and angina pectoris, and cerebrovascular diseases included all cases of stroke and TIA. 
As of the $1^{\text {st }}$ January 2019, participants with no history of CVD who had completed at least two valid 24-h dietary records were included in the analyses. Mean daily dairy intakes (overall and by type of dairy food) were coded as sex-specific quartiles, as potential distinctions in dietary patterns of French adult men and women have been previously reported ${ }^{(26),(27)}$. Missing values represented less than $5 \%$ for all covariates, except for physical activity, and were imputed with the modal or median value for categorical and continuous variables, respectively. Physical activity scores were only calculated when all the answers from the IPAQ were provided by the participants, which resulted in a higher percentage of missing value for this variable (13.9\%). Therefore, we introduced a missing class for this variable in the main analysis. Nonetheless, we performed additional analyses including complete cases and multiple imputation for missing values. We used the MICE method ${ }^{(28)}$ to create 10 imputed datasets with fully conditional specification for the outcome ${ }^{(29)}$ and the following covariates: physical activity level, education level, smoking status and BMI. We used the SAS PROC MIANALYZE procedure ${ }^{(30)}$ to combine the results from the imputed datasets, based on the combination rules proposed by Rubin ${ }^{(31),(32)}$.

Two dietary patterns were identified using a principal component analysis based on 20 food categories derived from the 58 food groups defined in the French PNNS (Appendix 1). The analysis was conducted with the SAS PROC FACTOR procedure (SAS Institute Inc, Cary, NC). For easier interpretation, we used the SAS "varimax" option to rotate the principal components orthogonally and maximise the independence of the retained principal components. The first two principal components explained $10.6 \%$ and $7.0 \%$ of the variance, respectively, which was consistent with proportion of variance observed in other nutritional epidemiology studies ${ }^{(33)}$. The first principal component was characterised by higher intakes of fruits, vegetables, soups and broths, unsweetened soft drinks, and wholegrains, along with lower intakes of sweetened soft drinks, which we defined as a "Healthy" dietary pattern. In contrast, the second principal component was characterised by higher consumptions of fats and sauces (which included butter and dairy cream), alcohol, meat, and starchy foods, which we defined as a "Western" dietary pattern. We calculated an adherence score to each dietary pattern and for each participant, using the food categories factor loadings to weigh the sum of all food categories observed consumption. Thus, the adherence score measures a participant's diet conformity to the identified dietary pattern.

Multivariable Cox proportional hazard models with age as the primary time variable were used to characterise the associations between each type of dairy consumption and incidence of CVD, CHD and cerebrovascular diseases, and to calculate cause-specific hazard ratios and $95 \%$ confidence intervals. In the CHD model, cerebrovascular disease cases were censored the date of diagnosis but were considered as non-cases for $\mathrm{CHD}$, and reciprocally for the cerebrovascular disease model. The Schoenfeld residuals were used to confirm risk proportionality assumptions ${ }^{(34)}$. P-values for linear trends were obtained by coding quartiles of dairy consumption as an ordinal variable. Participants contributed person-time to the Cox model until the date of CVD diagnosis, the date of the last completed questionnaire, the date of death or $1^{\text {st }}$ January 2019 , whichever occurred first. Models were adjusted for age (time-scale), sex, physical activity (low, moderate, high, missing, computed following IPAQ recommendations), BMI ( $\mathrm{kg} / \mathrm{m}^{2}$, continuous), education level (<highschool degree, $<2$ years after high-school degree, $\geq 2$ years after high-school degree), without alcohol energy intake ( $\mathrm{kcal} / \mathrm{d}$, continuous), alcohol intake (g/d, continuous), smoking status (never smoked, 
former smoker, current smoker), number of dietary records (continuous), family history of CVD (yes/no) (model 1).

In exploratory analyses, we performed two additional models to account for the potential influence of the nutritional quality of the diet. This included adjusting model 1 for a healthy dietary pattern derived from principal component analysis (Appendix 1) (model 2). Finally, further adjustments were added to model 1 to include the influence of baseline prevalence and treatment of self-reported type 2 diabetes, hypercholesterolemia, hypertension, and hypertriglyceridemia (model 3).

When Cox models revealed significant associations, sensitivity analyses were performed based on model 1 by adding further adjustments for a Western dietary pattern derived from principal component analysis (Appendix 1). Finally, CVD cases diagnosed in the first two years of each participant's follow-up were excluded to account for reverse causation bias in statistically significant associations. All tests were two-sided and $p$-values $\leq 0.05$ were considered statistically significant. All analyses were carried out with SAS software (version 9.4; SAS Institute Inc., Cary, NC).

\section{Results}

This analysis included 104,805 participants (see Figure 1. Flowchart) with a mean age of 42.8 years at baseline (SD 14.6), among which 22,291 were men (21.3\%) and 82,517 were women (78.7\%).

Participants included in this analysis had completed on average 5.7 (SD 3.1) 24h-dietary records, with $8.1 \%$ of the participants having only completed the minimum two dietary records for inclusion in the analyses. The participants' baseline characteristics according to sex-specific quartiles of dairy intake are shown in Table 1. Overall, there was no significant difference in baseline characteristics between low consumers ( $1^{\text {st }}$ quartile) and high consumers of dairy foods ( $4^{\text {th }}$ quartile). In addition, $65 \%$ of our participants had moderate to high physical activity scores from the IPAQ, $65.4 \%$ had $\geq 2$ years of education after high school and $82.8 \%$ did not smoke.

Participants consumed on average $222 \mathrm{~g} / \mathrm{d}$ of dairy foods (SD 151), including $110 \mathrm{~g} / \mathrm{d}$ of milk (SD 127), $37.7 \mathrm{~g} / \mathrm{d}$ of cheese (SD 28.3) and $79.1 \mathrm{~g} / \mathrm{d}$ of yogurt (SD 84.9), which was similar to the consumption levels observed in the general French population ${ }^{(9)}$. In addition, dairy foods contributed to $18.3 \%$ of total fat intakes (SD 13.7) and $28.9 \%$ of SFA intakes (SD 24.4) (Appendix 2).

\section{Associations between dairy consumption and CVD risk}

Between 2009 and 2019 and a mean follow-up of 5.5 years (SD 3.0, 579,155 person years), 2,098 cases of CVD were diagnosed, among which there were 1,220 cases of CHD (82 acute coronary syndromes, 318 angina pectoris, 148 myocardial infarctions and 672 angioplasties) and 878 cases of cerebrovascular diseases (118 strokes and 760 TIAs).

Schoenfeld residuals were not significantly associated with time, which supported the proportional hazard assumption (Appendix 3 ). The associations between the consumption of dairy foods and the risks of overall cardiovascular, coronary heart, and cerebrovascular diseases are presented in Table 2. The basic multivariable Cox proportional hazard (model 1 ) did not reveal any statistically significant association between the consumption of any dairy type and overall or coronary heart diseases. These associations remained statistically non-significant in models 2, 3 and 4 (data not 
shown). However, high consumption ( $\geq 161.6 \mathrm{~g} / \mathrm{d}$ for males and , $\geq 160.9 \mathrm{~g} / \mathrm{d}$ for females) of fermented dairy foods (yogurt, cheese and fermented milk) compared to low-consumption $(<57.3$ $\mathrm{g} / \mathrm{d}$ for males, $<54.3 \mathrm{~g} / \mathrm{d}$ for females) was associated with a $19 \%$ decreased risk of cerebrovascular disease $(\mathrm{HR}=0.81,95 \% \mathrm{Cl}=0.66-0.98, \mathrm{p}$-trend $=0.01)$. This association was borderline significant when considering the continuous intake of fermented dairy with an increment of $100 \mathrm{~g} / \mathrm{d}(\mathrm{HR}=0.98$, $95 \% \mathrm{Cl}=0.97-1.00, \mathrm{p}$-value $=0.05)$. In addition, the restricted cubic spline presented in Figure 2 verified the linearity assumption between the consumption of fermented dairy foods and the risk of cerebrovascular disease ( $p$-value for non-linear association $=0.23)^{(35)}$.

\section{Exploratory and Sensitivity analyses}

The association between fermented dairy consumption and cerebrovascular risk remained statistically significant when comparing the highest intake ( $4^{\text {th }}$ quartile) to the lowest intake ( $1^{\text {st }}$ quartile), after further adjustments in models 2 and 3 (Table 3). Similarly, this association remained stable in further exploratory analyses adjusting for a Western dietary pattern derived from principal component analysis ( $\mathrm{HR}=0.81,95 \% \mathrm{Cl}=0.66-0.98, \mathrm{p}$-trend=0.01). Furthermore, the use of multiple imputation with the MICE method to manage missing values strengthened the inverse association between continuous consumption of fermented foods and cerebrovascular disease risk (HR $=0.91$, $95 \% \mathrm{Cl}=0.84-0.99, \mathrm{p}$-value $=0.02$ ), but did not significantly impact other associations between continuous dairy consumption and overall, coronary heart or cerebrovascular disease risk. When excluding CVD cases that required more extensive documentation to ascertain diagnosis (i.e. TIAs and angina), all associations between dairy consumption and disease risk where non-significant, likely due to a loss of statistical power.

Finally, the exclusion of cerebrovascular disease cases diagnosed during the first two years of followup ( $n=144$ cases excluded) suggested a $9 \%$ decreased risk of cerebrovascular disease associated with each additional 100g of fermented dairy food consumed daily ( $n=734$ cases / 103,927 non cases, HR $=0.91,95 \% \mathrm{Cl}=0.83-0.99, \mathrm{p}$-trend $=0.03)$, and a $21 \%$ decreased risk when comparing the highest $\left(4^{\text {th }}\right.$ quartile) to the lowest $\left(1^{\text {st }}\right.$ quartile $)$ consumption of fermented dairy $(\mathrm{HR}=0.79,95 \% \mathrm{Cl}=0.64-0.98$, p-trend $=0.001$ ).

\section{Discussion}

In this prospective cohort study of French adults, we did not observe a statistically significant association between the consumption of dairy food and the risk of CVD or CHD. However, our results suggest a possible lower risk of cerebrovascular disease (i.e. stroke and TIA) associated with a higher consumption of fermented dairy foods, such as cheese and yogurts.

It is recommended to limit dietary SFA intakes for CVD prevention; however, this study did not reveal any direct association between the consumption of dairy products and total CVD or CHD risk, despite contributing to $28.9 \%$ of dietary SFA (Appendix $2 \mathrm{~b}$ ). This supports the existing epidemiological evidence on the topic, especially from meta-analyses of prospective studies which consistently reported null or weak inverse associations between the consumption of total dairy and 
CVD risk (10)-(13),(36). In a 2018 meta-analysis, Soedamah-Muthu and de Goede reported a nonstatistically significant association between total dairy and CHD risk when pooling the results from 15 prospective cohort studies, and reported an $8 \%$ reduced risk of stroke associated with an increment of $200 \mathrm{~g}$ of milk consumption per day (Risk Ratio $(\mathrm{RR})=0.92,95 \%$ confidence interval $(\mathrm{Cl})=0.88-0.97$, $\left.I^{2}=85 \%\right)^{(13)}$. Since then, the PURE prospective cohort study observed 5,855 CVD events over 9.1 years of follow-up from both urban and rural populations in 21 countries ${ }^{(14)}$. In this large prospective study, authors reported that a total dairy consumption of $>2$ servings per day, compared to no dairy consumption, was associated with a $22 \%$ risk reduction of major CVD (i.e. MI, stroke, or heart failure) (Hazard Ratio $(\mathrm{HR})=0.78,95 \% \mathrm{Cl}=0.67-0.90, \mathrm{p}$-trend $=0.0001$ ) and a $34 \%$ reduced risk of incident stroke $(\mathrm{HR}=0.66,95 \% \mathrm{Cl}=0.53-0.82$, $\mathrm{p}$-trend $=0.0003)$. More recently, a small prospective cohort study from Greece, which included 2,020 participants followed-up for 10 years, observed an inverse association between total dairy intake and total CVD risk $(\mathrm{HR}=0.48,95 \% \mathrm{Cl}=0.23-0.90)$ in women only. This inverse association in women was stronger when the authors looked at yogurt consumption, with a $14 \%$ CVD risk reduction associated with a $200 \mathrm{~g} / \mathrm{d}$ increment in yogurt intake $(\mathrm{HR}=0.86,95 \% \mathrm{Cl}=0.49-0.98)^{(37)}$.

The inverse association between fermented dairy and cerebrovascular risk observed in this study may suggest a differential effect of these types of dairy foods on cardiovascular health. In a 2019 meta-analysis of randomised controlled trials and prospective studies, Companys et al. observed that the consumption of fermented milk was associated with a reduced risk of stroke and ischemic heart disease $\left(\mathrm{RR}=0.96,95 \% \mathrm{Cl} 0.94 \text { to } 0.98 \text {, high heterogeneity } \mathrm{I}^{2}=95.9 \%\right)^{(38)}$. This finding was in line with those reported in an extensive review of meta-analyses conducted by Fontecha et al. in 2019, which observed a reduced risk of stroke and stroke mortality associated with the consumption of fermented dairy, including fermented milk ${ }^{(39)}$ and cheese ${ }^{(12),(39)-(42)}$, but not yogurt ${ }^{(10)}$.

Another potential source of variation in the health effects of dairy consumption relates to the nutrient content of specific types of dairy foods. In the large European EPIC-Netherlands study, Laursen et al. observed 884 stroke cases over a 15.2-year follow-up. They reported that the consumption of each additional daily serving of whole-fat yogurt as a substitution for any other dairy group (low-fat yogurt, cheese, butter, buttermilk or milk) was associated with a lower risk of ischemic stroke (HR between 0.33 and 0.36$)^{(43)}$. These findings were in line with previous results observed by the same authors in another European prospective study, the Danish Diet, Cancer and Health cohort ${ }^{(44)}$. However, emerging evidence suggest that the nutrient content of dairy should be considered in relation to the dairy food matrix, which refers to the physical structure of food and may have an impact on nutrient absorption and biomarkers of CVD risk, such as blood pressure and cholesterol metabolism. In particular, one hypothesis suggests that cheese, despite being high in fat, possesses similar features to milk and yogurt, rather than to butter, due to its high calcium, protein and milk fat globule membrane content ${ }^{(45)}$. In addition, the fermentation process involved in the production of cheese and yogurt often results in the presence of bacteria within the food matrix, which may produce short-chain fatty acids and bioactive peptides ${ }^{(45)}$. All these components of dairy, particularly present in cheese and yogurt, may interfere with the intestinal absorption and digestibility of fat (which is mostly SFA in dairy foods) and therefore attenuate the effect of SFA on cholesterol metabolism and potentially provide a protective effect on cardiovascular health ${ }^{(46)-(49)}$. 
these potential mechanisms, this would be in line with observational evidence from meta-analyses of prospective studies, which suggest that fermented dairy consumption may be associated with lower total and low-density lipoprotein cholesterol levels ${ }^{(50)-(53)}$. Finally, a potential hypotensive effect of bioactive peptides found in fermented dairy foods may reduce cerebrovascular diseases risk, which would be in line with observational epidemiological studies, but still needs further research to be fully elucidated ${ }^{(54)}$.

The prospective design of this study contributed to its strengths, allowing the assessment of midterm associations of dairy consumption with CVD risks. In addition, this study used repeated $24 \mathrm{~h}$ dietary records to provide detailed and up-to-date dietary intake assessment, as opposed to food frequency questionnaires which are often used in nutritional epidemiology. In this study, we identified two Healthy and Western dietary patterns using a principal component analysis (Appendix 1), and these patterns did not influence the associations observed between fermented dairy consumption and cerebrovascular risk. Finally, the use of the SNIIRAM national register allowed the maximisation of CVD case ascertainment, limiting the omission of cases when participants did not report their disease to the study investigators. However, some limitations of this study also pertain to its observational design. Indeed, residual confounding cannot be ruled out and a causal link between the consumption of fermented dairy and a decreased risk of cerebrovascular disease cannot be established from this prospective cohort study alone, although the inclusion of many potential confounders in our main analyses suggest a robust inverse association. Furthermore, a relatively limited statistical power precluded the investigation of specific types of CVDs. The NutriNet-Santé cohort is volunteered-based, and as highlighted in Table 1, the participants included in this study were generally more health-conscious, younger, more highly educated, more often women, consumed more fruits and vegetables ${ }^{(9)}$ and were less likely to smoke or be overweight ${ }^{(55)}$, compared to the general French population.

In conclusion, in this large prospective cohort study we found that the consumption of dairy foods may not be associated with overall CVD or CHD risks in French adults. However, we observed a higher consumption of fermented dairy products (e.g. cheese and yogurt) to be associated with a lower risk of stroke and TIA. Overall, these observational findings provide insight on the potential role of specific dairy foods in cardiometabolic health, although future RCT are warranted to confirm these associations. 


\section{Acknowledgments}

The authors warmly thank all the volunteers of the NutriNet-Sante cohort. We also thank Younes Esseddik (IT manager), Thi Hong Van Duong, Régis Gatibelza, and Jagatjit Mohinder (computer scientists), Fabien Szabo de Edelenyi, PhD (data management supervisor), Julien Allègre, Nathalie Arnault, Laurent Bourhis (data-managers/biostatisticians), Sandrine Kamdem, MD (physician), and Nathalie Druesne-Pecollo (operational coordinator) for their technical contribution to the NutriNetSanté study.

\section{Financial Support}

The NutriNet-Santé study was supported by the Ministère de la Santé, Santé Publique France, Institut National de la Santé et de la Recherche Médicale (INSERM), Institut National de la Recherche Agronomique (INRA), Conservatoire National des Arts et Métiers (CNAM), and Université Paris 13. Laury Sellem was funded by the Biotechnology and Biological Sciences Research Council (BBSRC) Joint Programme Initiatives (JPI) "HDHL Biomarkers: Fatty Acid Metabolism - Interlinking Diet with Cardiometabolic Health (FAME)" (Project Reference: BB/P028217/1). Researchers were independent from funders. Funders had no role in the study design, the collection, analysis, and interpretation of data, the writing of the report, and the decision to submit the article for publication.

\section{Conflicts of Interests/Competing Interests}

Julie Lovegrove is Deputy Chair of the UK Scientific Advisory Committee for Nutrition (SACN) and was an expert on SACN's Saturated Fats working group. All others have no conflict of interest to declare.

\section{Authors' contributions}

LS, MT and JL designed the research. SH, PG, MT, CJ, LKF and EK-G conducted the research. LS performed the statistical analyses. BS supervised the statistical analyses. LS drafted the manuscript. $M S, J L$ and KGJ supervised the writing. BS, KGJ, SH, PG, EK-G, CJ, LKF, MD, JL and MT contributed to the data interpretation and revised each draft for important intellectual content. All authors read and approved the final manuscript. MT and JL had primary responsibility for the final content and are the guarantors. The corresponding author (BS) attests that all listed authors meet authorship criteria and that no other authors meeting criteria have been omitted.

\section{References}

1. World Health Organization. Cardiovascular diseases [Internet]. 2020 [cited 2020 Aug 11]. Available from: https://www.who.int/westernpacific/health-topics/cardiovascular-diseases

2. Vos T, Lim SS, Abbafati C, et al. Global burden of 369 diseases and injuries in 204 countries and territories, 1990-2019: a systematic analysis for the Global Burden of Disease Study 2019. The Lancet. 2020 Oct 17;396(10258):1204-22.

3. Santé Publique France. Cardiovascular diseases - Public Health France (Santé Publique France) [Internet]. [cited 2020 Aug 11]. Available from: /maladies-et-traumatismes/maladiescardiovasculaires-et-accident-vasculaire-cerebral 
4. GBD 2017 Diet Collaborators. Health effects of dietary risks in 195 countries, 1990-2017: a systematic analysis for the Global Burden of Disease Study 2017. Lancet. 2019 11;393(10184):1958-72.

5. Borén J, Chapman MJ, Krauss RM, et al. Low-density lipoproteins cause atherosclerotic cardiovascular disease: pathophysiological, genetic, and therapeutic insights: a consensus statement from the European Atherosclerosis Society Consensus Panel. Eur Heart J. 2020 Jun 21;41(24):2313-30.

6. Kaptoge S, Pennells L, De Bacquer D, et al. World Health Organization cardiovascular disease risk charts: revised models to estimate risk in 21 global regions. Lancet Glob Health. 2019 Sep 2;7(10):e1332-45.

7. ANSES. Fats | Anses - Agence nationale de sécurité sanitaire de l'alimentation, de l'environnement et du travail [Internet]. 2016 [cited 2017 Jun 8]. Available from: https://www.anses.fr/en/content/fats

8. Chaltiel D, Adjibade M, Deschamps V, et al. Programme National Nutrition Santé - guidelines score 2 (PNNS-GS2): development and validation of a diet quality score reflecting the 2017 French dietary guidelines. Br J Nutr. 2019 14;122(3):331-42.

9. ANSES. Third Individual and National Survey on Food Consumption (INCA3) [Internet]. 2017 Jun [cited 2020 Aug 13]. Available from:

https://www.anses.fr/fr/system/files/NUT2014SA0234Ra.pdf

10. Fontecha J, Calvo MV, Juarez M, et al. Milk and Dairy Product Consumption and Cardiovascular Diseases: An Overview of Systematic Reviews and Meta-Analyses. Adv Nutr. 2019 May 1;10(suppl_2):S164-89.

11. Guo J, Astrup A, Lovegrove JA, et al. Milk and dairy consumption and risk of cardiovascular diseases and all-cause mortality: dose-response meta-analysis of prospective cohort studies. European Journal of Epidemiology. 2017;32(4):269-87.

12. Alexander DD, Bylsma LC, Vargas AJ, et al. Dairy consumption and CVD: a systematic review and meta-analysis. British Journal of Nutrition. 2016 Feb;115(4):737-50.

13. Soedamah-Muthu SS, de Goede J. Dairy Consumption and Cardiometabolic Diseases: Systematic Review and Updated Meta-Analyses of Prospective Cohort Studies. Curr Nutr Rep. 2018;7(4):171-82.

14. Dehghan M, Mente A, Rangarajan S, et al. Association of dairy intake with cardiovascular disease and mortality in 21 countries from five continents (PURE): a prospective cohort study. The Lancet. 2018 Nov 24;392(10161):2288-97.

15. Hercberg S, Castetbon K, Czernichow S, et al. The Nutrinet-Santé Study: a web-based prospective study on the relationship between nutrition and health and determinants of dietary patterns and nutritional status. BMC Public Health. 2010 May 11;10:242.

16. Vergnaud A-C, Touvier M, Méjean $C$, et al. Agreement between web-based and paper versions of a socio-demographic questionnaire in the NutriNet-Santé study. Int J Public Health. 2011 Aug;56(4):407-17. 
17. Lassale $C$, Péneau S, Touvier M, et al. Validity of web-based self-reported weight and height: results of the Nutrinet-Santé study. J Med Internet Res. 2013 Aug 8;15(8):e152.

18. Touvier M, Méjean C, Kesse-Guyot E, et al. Comparison between web-based and paper versions of a self-administered anthropometric questionnaire. Eur J Epidemiol. 2010 May;25(5):287-96.

19. Lassale C, Castetbon K, Laporte F, et al. Validation of a Web-based, self-administered, nonconsecutive-day dietary record tool against urinary biomarkers. Br J Nutr. 2015 Mar 28;113(6):953-62.

20. IPAQ Group. Guidelines for Data Processing and Analysis of the International Physical Activity Questionnaire (IPAQ). 2005.

21. Craig CL, Marshall AL, Sjöström M, et al. International physical activity questionnaire: 12country reliability and validity. Med Sci Sports Exerc. 2003 Aug;35(8):1381-95.

22. Touvier M, Kesse-Guyot E, Méjean C, et al. Comparison between an interactive web-based selfadministered $24 \mathrm{~h}$ dietary record and an interview by a dietitian for large-scale epidemiological studies. Br J Nutr. 2011 Apr;105(7):1055-64.

23. Le Moullec N, Deheeger M, Preziosi P, et al. Validation du manuel photo utilisé pour l'enquête alimentaire de l'étude SU.VI.MAX. [Validation of the food portion size booklet used in the SU.VI.MAX study]. Cahiers de Nutrition et de Diététique. 1996;31:158-64.

24. Arnault N, Caillot L, Castetbon K, et al. Table de composition des aliments, étude NutriNetSanté. [Food composition table, NutriNet-Santé study] (in French). 2013;

25. Black AE. Critical evaluation of energy intake using the Goldberg cut-off for energy intake:basal metabolic rate. A practical guide to its calculation, use and limitations. Int J Obes Relat Metab Disord. 2000 Sep;24(9):1119-30.

26. Kesse-Guyot E, Bertrais S, Péneau S, et al. Dietary patterns and their sociodemographic and behavioural correlates in French middle-aged adults from the SU.VI.MAX cohort. European Journal of Clinical Nutrition. 2009 Apr;63(4):521-8.

27. Gazan R, Béchaux $C$, Crépet A, et al. Dietary patterns in the French adult population: a study from the second French national cross-sectional dietary survey (INCA2) (2006-2007). Br J Nutr. 2016 Jul 28;116(2):300-15.

28. van Buuren S. Multiple imputation of discrete and continuous data by fully conditional specification. Stat Methods Med Res. 2007 Jun 1;16(3):219-42.

29. Sterne JAC, White IR, Carlin JB, et al. Multiple imputation for missing data in epidemiological and clinical research: potential and pitfalls. BMJ [Internet]. 2009 Jun 29 [cited $2020 \mathrm{Apr}$ 21];338. Available from: https://www.bmj.com/content/338/bmj.b2393

30. SAS/STAT 14.3 User's guide. SAS Help Center: PROC MI Statement [Internet]. [cited 2020 Apr 21]. Available from: https://documentation.sas.com/?docsetld=statug\&docsetTarget=statug_mi_syntax01.htm\&do csetVersion=14.3\&locale $=$ en 
31. Rubin DB. Multiple Imputation for Nonresponse in Surveys. In: Multiple Imputation for Nonresponse in Surveys [Internet]. John Wiley \& Sons, Ltd; 2004 [cited 2020 Apr 21]. p. i-xxix. Available from: https://onlinelibrary.wiley.com/doi/abs/10.1002/9780470316696.fmatter

32. Rubin DB. Inference and missing data. Biometrika. 1976 Dec 1;63(3):581-92.

33. Santos R de O, Gorgulho BM, Castro MA de, et al. Principal Component Analysis and Factor Analysis: differences and similarities in Nutritional Epidemiology application. Rev Bras Epidemiol. 2019 Jul 29;22:e190041.

34. Schoenfeld D. Partial residuals for the proportional hazards regression model. Biometrika. 1982 Apr 1;69(1):239-41.

35. Desquilbet L, Mariotti F. Dose-response analyses using restricted cubic spline functions in public health research. Statistics in Medicine. 2010;29(9):1037-57.

36. Gille D, Schmid A, Walther B, et al. Fermented Food and Non-Communicable Chronic Diseases: A Review. Nutrients. 2018 Apr;10(4):448.

37. Kouvari M, Panagiotakos DB, Chrysohoou C, et al. Dairy products, surrogate markers, and cardiovascular disease; a sex-specific analysis from the ATTICA prospective study. Nutrition, metabolism, and cardiovascular diseases: NMCD. 2020 Jul 31;

38. Companys J, Pla-Pagà L, Calderón-Pérez L, et al. Fermented Dairy Products, Probiotic Supplementation, and Cardiometabolic Diseases: A Systematic Review and Meta-analysis. Advances in Nutrition (Bethesda, Md). 2020 01;11(4):834-63.

39. Hu D, Huang J, Wang Y, et al. Dairy foods and risk of stroke: a meta-analysis of prospective cohort studies. Nutr Metab Cardiovasc Dis. 2014 May;24(5):460-9.

40. Chen G-C, Wang $Y$, Tong $X$, et al. Cheese consumption and risk of cardiovascular disease: a meta-analysis of prospective studies. Eur J Nutr. 2017 Dec 1;56(8):2565-75.

41. Gholami F, Khoramdad M, Esmailnasab N, et al. The effect of dairy consumption on the prevention of cardiovascular diseases: A meta-analysis of prospective studies. J Cardiovasc Thorac Res. 2017;9(1):1-11.

42. Qin L-Q, Xu J-Y, Han S-F, et al. Dairy consumption and risk of cardiovascular disease: an updated meta-analysis of prospective cohort studies. Asia Pac J Clin Nutr. 2015;24(1):90-100.

43. Laursen ASD, Sluijs I, Boer JMA, et al. Substitutions between dairy products and risk of stroke: results from the European Investigation into Cancer and Nutrition-Netherlands (EPIC-NL) cohort. The British Journal of Nutrition. 2019;121(12):1398-404.

44. Laursen ASD, Dahm CC, Johnsen SP, et al. Substitutions of dairy product intake and risk of stroke: a Danish cohort study. Eur J Epidemiol. 2018 Feb 1;33(2):201-12.

45. Thorning TK, Bertram HC, Bonjour J-P, et al. Whole dairy matrix or single nutrients in assessment of health effects: current evidence and knowledge gaps. Am J Clin Nutr. 2017 May 1;105(5):1033-45. 
46. Soerensen KV, Thorning TK, Astrup A, et al. Effect of dairy calcium from cheese and milk on fecal fat excretion, blood lipids, and appetite in young men. Am J Clin Nutr. 2014 May;99(5):984-91.

47. Raziani $F$, Tholstrup $T$, Kristensen MD, et al. High intake of regular-fat cheese compared with reduced-fat cheese does not affect LDL cholesterol or risk markers of the metabolic syndrome: a randomized controlled trial. Am J Clin Nutr. 2016;104(4):973-81.

48. Wolever TM, Fernandes J, Rao AV. Serum acetate:propionate ratio is related to serum cholesterol in men but not women. J Nutr. 1996 Nov;126(11):2790-7.

49. Crippa G, Zabzuni D, Bravi E, et al. Randomized, double blind placebo-controlled pilot study of the antihypertensive effects of Grana Padano D.O.P. cheese consumption in mild - moderate hypertensive subjects. Eur Rev Med Pharmacol Sci. 2018;22(21):7573-81.

50. Agerholm-Larsen L, Bell ML, Grunwald GK, et al. The effect of a probiotic milk product on plasma cholesterol: a meta-analysis of short-term intervention studies. Eur J Clin Nutr. 2000 Nov;54(11):856-60.

51. Sun J, Buys N. Effects of probiotics consumption on lowering lipids and CVD risk factors: a systematic review and meta-analysis of randomized controlled trials. Ann Med. 2015;47(6):430-40.

52. de Goede J, Geleijnse JM, Ding EL, et al. Effect of cheese consumption on blood lipids: a systematic review and meta-analysis of randomized controlled trials. Nutr Rev. 2015 May;73(5):259-75.

53. Shimizu M, Hashiguchi M, Shiga T, et al. Meta-Analysis: Effects of Probiotic Supplementation on Lipid Profiles in Normal to Mildly Hypercholesterolemic Individuals. PLoS One. 2015;10(10):e0139795.

54. Melini F, Melini V, Luziatelli F, et al. Health-Promoting Components in Fermented Foods: An Up-to-Date Systematic Review. Nutrients [Internet]. 2019 May 27 [cited 2020 Oct 13];11(5). Available from: https://www.ncbi.nlm.nih.gov/pmc/articles/PMC6567126/

55. Andreeva VA, Salanave B, Castetbon K, et al. Comparison of the sociodemographic characteristics of the large NutriNet-Santé e-cohort with French Census data: the issue of volunteer bias revisited. J Epidemiol Community Health. 2015 Sep;69(9):893-8. 
Table 1. Baseline characteristics of study population according to sex-specific quartiles of dairy consumption, NutriNet-Santé cohort, France, 2009-2019 ( $n=104,805)$.

\begin{tabular}{|c|c|c|c|c|c|c|c|c|c|c|c|}
\hline \multirow{3}{*}{$\begin{array}{l}\text { Characteristics } \\
\text { Age, years }\end{array}$} & \multicolumn{10}{|c|}{ Quartiles of total dairy intake a } & \multirow{3}{*}{$\begin{array}{l}\text { P-value b } \\
0.89\end{array}$} \\
\hline & \multicolumn{2}{|c|}{$\begin{array}{l}\text { All participants } \\
(n=104,805)\end{array}$} & \multicolumn{2}{|c|}{$\begin{array}{l}\text { First (n=26,201) } \\
\text { (lowest intake) }\end{array}$} & \multicolumn{2}{|c|}{$\begin{array}{c}\text { Second } \\
(n=26,202)\end{array}$} & \multicolumn{2}{|c|}{$\begin{array}{c}\text { Third } \\
(n=26,203)\end{array}$} & \multicolumn{2}{|c|}{$\begin{array}{c}\text { Fourth (n=26,202) } \\
\text { (highest intake) }\end{array}$} & \\
\hline & 42.8 & 14.6 & 42.7 & 14.6 & 42.8 & 14.6 & 42.8 & 14.6 & 42.8 & 14.6 & \\
\hline Sex & & & & & & & & & & & 1.00 \\
\hline Female, $n$ & 82,517 & 78.7 & 20,629 & 78.7 & 20,629 & 78.7 & 20,630 & 78.7 & 20,629 & 78.7 & \\
\hline Male, $n$ & 22,291 & 21.3 & 5,572 & 21.3 & 5,573 & 21.3 & 5,573 & 21.3 & 5,573 & 21.3 & \\
\hline $\mathrm{BMI}, \mathrm{kg} / \mathrm{m}^{2}$ & 23.7 & 4.5 & 23.7 & 4.5 & 23.7 & 4.5 & 23.7 & 4.5 & 23.7 & 4.4 & 0.11 \\
\hline Physical Activity c & & & & & & & & & & & 0.97 \\
\hline Low & 2,2049 & 21.0 & 5,439 & 20.8 & 5,513 & 21.0 & 5,538 & 21.1 & 5,559 & 21.2 & \\
\hline Moderate & 3,8712 & 36.9 & 9,710 & 37.1 & 9,676 & 36.9 & 9,633 & 36.8 & 9,693 & 37.0 & \\
\hline High & 2,9447 & 28.1 & 7,366 & 28.1 & 7,376 & 28.2 & 7,370 & 28.1 & 7,335 & 28.0 & \\
\hline Education level & & & & & & & & & & & 0.55 \\
\hline$<$ High school degree & 18,323 & 17.5 & 4,545 & 17.4 & 4,543 & 17.3 & 4,617 & 17.6 & 4,618 & 17.6 & \\
\hline $\begin{array}{l}<2 \text { years after high } \\
\text { school }\end{array}$ & 17,969 & 17.1 & 4,571 & 17.5 & 4,474 & 17.1 & 4,516 & 17.2 & 4,408 & 16.8 & \\
\hline $\begin{array}{l}\geq 2 \text { years after high } \\
\text { school }\end{array}$ & 68,516 & 65.4 & 17,085 & 65.2 & 17,185 & 65.6 & 17,070 & 65.2 & 17,176 & 65.6 & \\
\hline Smoking status & & & & & & & & & & & 0.66 \\
\hline Never & 52,325 & 49.9 & 13,093 & 50.0 & 13,139 & 50.2 & 13,033 & 49.7 & 13,060 & 49.8 & \\
\hline Former & 34,479 & 32.9 & 8,607 & 32.8 & 8,567 & 32.6 & 8,595 & 32.8 & 8,710 & 33.3 & \\
\hline Current & 18,004 & 17.2 & 4,501 & 17.2 & 4,496 & 17.2 & 4,575 & 17.5 & 4,432 & 16.9 & \\
\hline $\begin{array}{l}\text { Family history of CVD }{ }^{d} \text {, } \\
\text { yes }\end{array}$ & 32,760 & 31.3 & 8,267 & 31.6 & 8,138 & 31.1 & 8,121 & 31.0 & 8,234 & 31.4 & 0.43 \\
\hline \multicolumn{12}{|l|}{ Prevalent morbidity, yes } \\
\hline Type 2 diabetes & 1,498 & 1.4 & 357 & 1.4 & 348 & 1.3 & 425 & 1.6 & 368 & 1.4 & 0.02 \\
\hline Hypertension & 8,691 & 8.3 & 2,100 & 8.0 & 2,224 & 8.5 & 2,170 & 8.3 & 2,197 & 8.4 & 0.23 \\
\hline Hypercholesterolemia & 8,396 & 8.0 & 2,073 & 8.0 & 2,135 & 8.0 & 2,097 & 8.0 & 2,091 & 8.0 & 0.79 \\
\hline Hypertriglyceridemia & 1,536 & 1.5 & 383 & 1.5 & 378 & 1.4 & 390 & 1.5 & 385 & 1.5 & 0.98 \\
\hline \multicolumn{12}{|l|}{ Intakes of: e } \\
\hline Energy, $\mathrm{kcal} / \mathrm{d}$ & 1,847 & 452 & 1,850 & 456 & 1,845 & 450 & 1,845 & 452 & 1,847 & 451 & 0.47 \\
\hline Alcohol, $g / d$ & 7.8 & 11.9 & 7.7 & 11.9 & 7.7 & 11.8 & 7.9 & 12.0 & 7.8 & 11.9 & 0.33 \\
\hline Total lipids, $g / d$ & 81.5 & 25.3 & 81.6 & 25.6 & 81.3 & 25.2 & 81.4 & 25.3 & 81.6 & 25.2 & 0.39 \\
\hline Carbohydrates, $g / d$ & 198.1 & 57.6 & 198.7 & 57.8 & 197.8 & 57.2 & 198.0 & 57.6 & 197.9 & 57.7 & 0.30 \\
\hline Proteins, $g / d$ & 78.8 & 21.5 & 78.9 & 21.6 & 79.0 & 21.5 & 78.7 & 21.4 & 78.8 & 21.5 & 0.58 \\
\hline Sodium, $g / d$ & 2.7 & 0.9 & 2.7 & 0.9 & 2.7 & 0.9 & 2.7 & 0.9 & 2.7 & 0.9 & 0.70 \\
\hline Total dietary fibre, $g / d$ & 19.5 & 7.2 & 19.5 & 7.2 & 19.5 & 7.1 & 19.5 & 7.3 & 19.4 & 7.2 & 0.54 \\
\hline Dietary Calcium, $m g / d$ & 921 & 299 & 922 & 299 & 922 & 299 & 919 & 299 & 921 & 299 & 0.61 \\
\hline $\begin{array}{l}\text { Fruits and Vegetables, } \\
g / d\end{array}$ & 465 & 233 & 467 & 231 & 465 & 231 & 467 & 237 & 463 & 231 & 0.14 \\
\hline Total dairy, $g / d$ & 222 & 151 & 65 & 32 & 150 & 22 & 241 & 32 & 431 & 123 & $<0.001$ \\
\hline Milk, serving/d & 0.55 & 0.81 & 0.56 & 0.82 & 0.55 & 0.81 & 0.55 & 0.81 & 0.55 & 0.82 & 0.56 \\
\hline Cheese, serving/d & 1.23 & 0.93 & 1.23 & 0.93 & 1.23 & 0.94 & 1.22 & 0.92 & 1.23 & 0.94 & 0.74 \\
\hline Yogurt, serving/d & 0.47 & 0.55 & 0.09 & 0.16 & 0.38 & 0.33 & 0.64 & 0.51 & 0.77 & 0.77 & $<0.001$ \\
\hline
\end{tabular}

All values are presented as means \pm SDs or $n(\%)$.

Abbreviations: CVD, cardiovascular disease. d, day.

${ }^{a}$ Sex-specific quartiles of total dairy consumption. Cut-offs were 112, 190 and 303g/d for males and 112, 191 and 301g/d for females. 
${ }^{b} \mathrm{P}$-value comparing quartiles of total dairy consumption, using two-sided $\chi^{2}$ tests or Fisher tests as appropriate.

c Physical activity categories according to the International Physical Activity Questionnaire (IPAQ) (20) IPAQ data was missing for 14,600 participants (13.9\%).

d Amongst first-degree relatives.

e Standard French serving sizes defined as $150 \mathrm{ml}$ for milk, $30 \mathrm{~g}$ for cheese and $125 \mathrm{~g}$ for yogurts. 
Table 2. Associations between dairy consumption and cardiovascular disease risk from multivariable Cox proportional hazard models ${ }^{\text {, }}$, NutriNet-Santé cohort, France, 2009-2019 ( $\left.n=104,805\right)$.

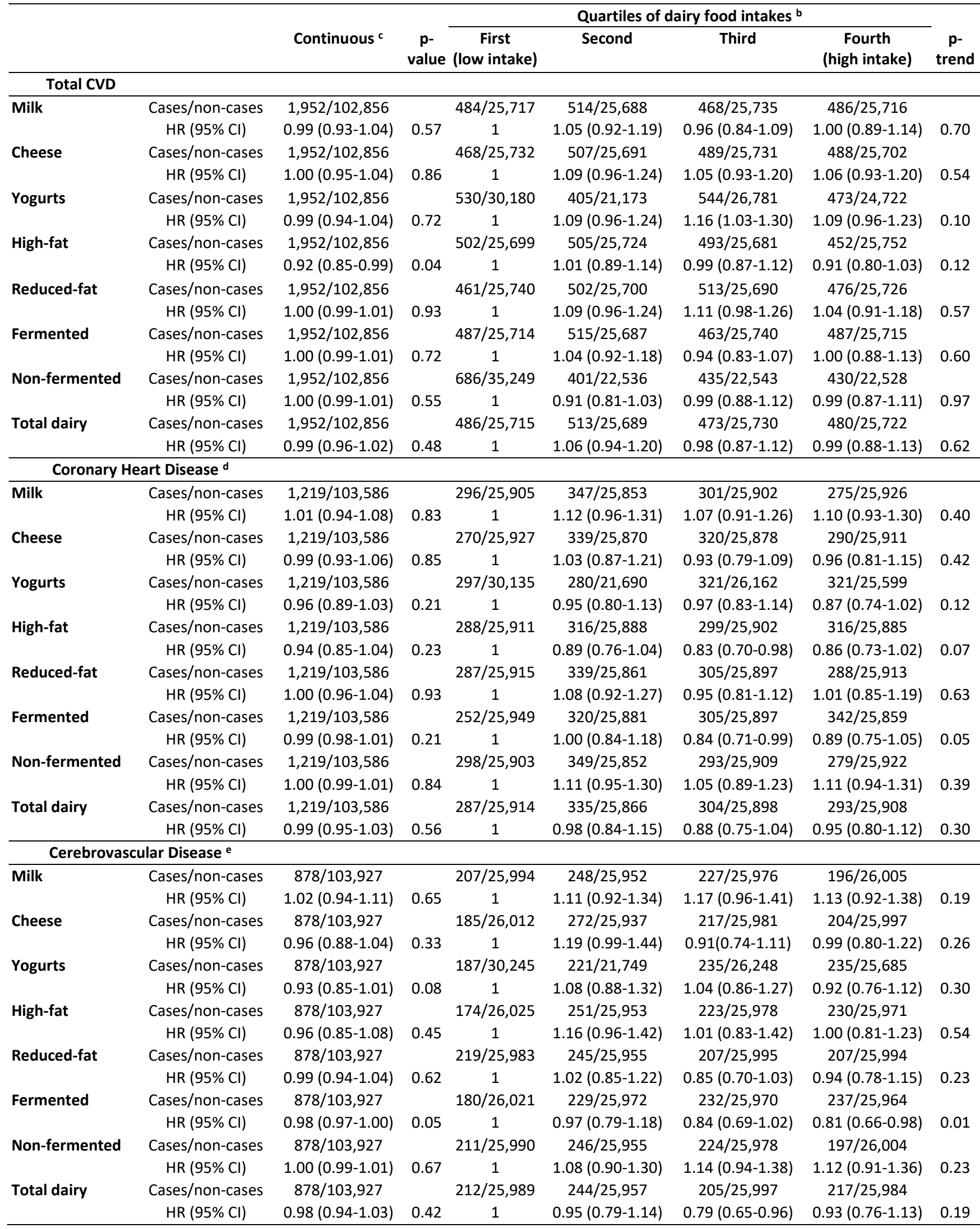


Abbreviations: CVD, cardiovascular disease. HR, hazard ratio. Cl, confidence interval.

${ }^{a}$ Cox models were adjusted for age (time-scale), sex, physical activity (low, moderate, high, computed following IPAQ recommendations), BMI (kg/m²,

continuous), education level (<high-school degree, <2 years after high-school degree, $\geq 2$ years after high-school degree), without alcohol energy intake (kcal/d, continuous), alcohol intake (g/d, continuous), smoking status (never smoked, former smoker, current smoker), number of dietary records (continuous), family history of CVD (yes/no) (model 1).

${ }^{\text {b }}$ Sex specific cut-offs for milk were $16.1,51.6$ and $153.8 \mathrm{~g} / \mathrm{d}$ in males and 16.3, 50.8 and $153.7 \mathrm{~g} / \mathrm{d}$ in females. Cut-offs for cheese were $17.7,32.9$ and $51.4 \mathrm{~g} / \mathrm{d}$ in males and $17.8,33.0$ and $51.6 \mathrm{~g} / \mathrm{d}$ in females. Cut-offs for yogurt-like dairy were $0.04,44.7$ and $109.8 \mathrm{~g} / \mathrm{d}$ in males and $11.9,60.2$ and $125.0 \mathrm{~g} / \mathrm{d}$ in females. Cutoffs for high-fat dairy were $26.2,50.5$ and $84.6 \mathrm{~g} / \mathrm{d}$ in males and $26.3,50.0$ and $83.9 \mathrm{~g} / \mathrm{d}$ in females. Cut-offs for reduced-fat dairy were $46.7,117.7$ and $232.9 \mathrm{~g} / \mathrm{d}$ for males and 47.1, 117.4 and $232.3 \mathrm{~g} / \mathrm{d}$ in females. Cut-offs for fermented dairy were 57.3, 102.8, 161.6 g/d for males and 54.3, 100.6 and 160.9 g/d in females. Cut-offs for non-fermented dairy were $16.8,54.3$ and $168.6 \mathrm{~g} / \mathrm{d}$ in males and $15.9,48.8$ and $147.5 \mathrm{~g} / \mathrm{d}$ in females. Cut-offs for total dairy were $112.0,186.8$ and $303.0 \mathrm{~g} / \mathrm{d}$ in males and $111.7,190.8$ and $301.5 \mathrm{~g} / \mathrm{d}$ in females.

c Hazard Ratios for an absolute increment of $150 \mathrm{~g} / \mathrm{d}$ of milk, $30 \mathrm{~g} / \mathrm{d}$ of cheese, and $100 \mathrm{~g} / \mathrm{d}$ of yogurts, high-fat, reduced-fat, fermented, non-fermented and total dairy.

d Includes myocardial infarction, angioplasty, acute coronary syndrome, and angina pectoris.

e Includes stroke and transient ischemic attack. 
Table 3. Associations between fermented dairy foods and cerebrovascular disease risk from multivariable Cox proportional hazard models, NutriNetSanté cohort, France, 2009-2019 ( $\mathrm{n}=104,805)$. ${ }^{2}$

\begin{tabular}{|c|c|c|c|c|c|c|}
\hline \multirow[b]{2}{*}{$\begin{array}{l}\text { Proportional hazard } \\
\text { Cox models }{ }^{b, c}\end{array}$} & & \multicolumn{4}{|c|}{ Quartiles of fermented dairy food intakes ${ }^{d}$} & \multirow[b]{2}{*}{ p-trend } \\
\hline & & $\begin{array}{c}\text { First } \\
\text { (low intake) }\end{array}$ & Second & Third & $\begin{array}{c}\text { Fourth } \\
\text { (high intake) }\end{array}$ & \\
\hline & Cases/non-cases & $180 / 26,021$ & $229 / 25,972$ & $232 / 25,970$ & $237 / 25,964$ & \\
\hline Model 1 & $\mathrm{HR}(95 \% \mathrm{Cl})$ & 1 & $0.97(0.79-1.18)$ & $0.84(0.69-1.02)$ & $0.81(0.66-0.98)$ & 0.01 \\
\hline Model 2 & HR $(95 \% \mathrm{Cl})$ & 1 & $0.97(0.79-1.18)$ & $0.84(0.69-1.02)$ & $0.81(0.66-0.98)$ & 0.01 \\
\hline Model 2b & HR (95\% Cl) & 1 & $0.97(0.79-1.18)$ & $0.84(0.69-1.02)$ & $0.81(0.66-0.98)$ & 0.01 \\
\hline Model 3 & HR (95\% Cl) & 1 & $0.96(0.79-1.17)$ & $0.83(0.68-1.02)$ & $0.80(0.66-0.98)$ & 0.01 \\
\hline
\end{tabular}

Abbreviations: HR, hazard ratio. $\mathrm{Cl}$, confidence interval.

a Cerebrovascular disease included incident events of strokes and transient ischemic attacks.

${ }^{b}$ Cox models were adjusted for age (time-scale), sex, physical activity (low, moderate, high, computed following IPAQ recommendations), BMI (kg/m² continuous), education level (<high-school degree, $<2$ years after high-school degree, $\geq 2$ years after high-school degree), without alcohol energy intake (kcal/d, continuous), alcohol intake (g/d, continuous), smoking status (never smoked, former smoker, current smoker), number of dietary records (continuous), family history of CVD (yes/no) (model 1). Model $\mathbf{2}=$ Model $1+$ healthy dietary pattern (derived by principal component analysis). Model $\mathbf{2 b = M o d e l} 1+$ Western dietary pattern derived by principal component analysis. Model 3=Model $1+$ prevalence and treatment of type 2 diabetes, dyslipidaemia, hypertension and hypertriglyceridemia.

c Hazard Ratios for an absolute increment of $100 \mathrm{~g} / \mathrm{d}$ of fermented dairy foods

d Sex specific cut-offs for fermented dairy were 57.3, 102.8, 161.6 g/d for males and 54.3, 100.6 and $160.9 \mathrm{~g} / \mathrm{d}$ in females. Fermented dairy foods included yogurt, cheese and fermented milk. 


\section{Figures legends (Supplementary material)}

Figure 1. Flowchart of participants included in the study, NutriNet-Santé cohort, France, 2009-2019

Figure 2. Spline plot for the linearity assumption of the association between the consumption of dairy foods and risk of cardiovascular diseases, NutriNet-Santé cohort, France, 2009-2019 ( $n=104,805){ }^{\text {a }}$

a) Consumption of fermented dairy and risk of cerebrovascular diseases

b) Consumption of total dairy and risk of total CVD

${ }^{a}$ Restricted cubic spline SAS macro developed by Desquilbet and Mariotti (35). 